\title{
Cross Cultural Experiences of Chinese Students Studying Food Science in Ireland
}

\author{
Maurice G. O'Sullivan1*, Briony Supple², Marian McCarthy² \\ ${ }^{1}$ Sensory Science, School of Food and Nutritional Sciences, University College Cork, Cork, Ireland \\ ${ }^{2}$ Centre for the Integration of Research, Teaching and Learning (CIRTL), Office of the Vice President for Teaching and Learning, \\ University College Cork, Cork, Ireland \\ Email: ^maurice.osullivan@ucc.ie
}

How to cite this paper: O'Sullivan, M. G., Supple, B., \& McCarthy, M. (2018). Cross Cultural Experiences of Chinese Students Studying Food Science in Ireland. Creative Education, 9, 1996-2015.

https://doi.org/10.4236/ce.2018.913146

Received: August 30, 2018

Accepted: October 22, 2018

Published: October 25, 2018

Copyright (c) 2018 by authors and Scientific Research Publishing Inc. This work is licensed under the Creative Commons Attribution International License (CC BY 4.0).

http://creativecommons.org/licenses/by/4.0/

cc) (i) Open Access

\begin{abstract}
This study focuses on the specific needs of Chinese students studying food science in UCC in order to provide better teaching and learning tools for students. Semi-structured individual interviews were used to establish the pros and cons of their learning experiences. The students interviewed showed consensus, such as: it is essential that they receive lecture notes with an adequate lead time so that they can pre-read and translate sections. They must have good WIFI access to facilitate real-time online translation. In order to speed and ease their transition into the Irish higher education system it is necessary to provide tutorials to Chinese students for the unfamiliar essay exam question format.
\end{abstract}

\section{Keywords}

Chinese, Student, Cross-Cultural, Structured Interview, Tools,

Teaching and Learning

\section{Introduction}

Food science is the comprehensive study of food and beverages or more specifically the application of the scientific disciplines of the physical, biological, and chemical as well as engineering, microbiology and nutrition to the study of food and beverages to improve the sensory properties, safety, nutrition, functionality, sustainability and availability. UCC attracts diverse cross-cultural groups of students to degree programmes in Ireland annually including 3000 international students from over 100 countries (UCC, 2018). The Food Science degree course in the School of Food and Nutritional Sciences constitutes one of the leading courses of its kind in Europe and for this reason, attracts a moderate cohort 
from China. Typically, these students have integrated into the existing degree programme. However, anecdotally, students were underperforming for some of their formative assessments due to a lack of familiarity with the Irish teaching system. For this reason, it was decided to investigate, from first principals, the experiences of these Chinese students both from their Chinese and Irish experiential perspectives in order to determine areas that could be optimised to improve their integration and promote their holistic learning experiences. The action research findings of this present study will thus be used to optimise a new bespoke degree programme, specifically catered for Chinese students, that commenced in UCC in September 2017.

\section{Literature Review}

Culture is defined as the knowledge, customs and language a group of people share, and it is formed over many generations (Kittler, Sucher, \& Nelms, 2011). Culture is passed on from generation to generation through socialization. Understanding the culture of others is very important in today's global society. It helps to maintain harmonious relations and is good for the cultural, technological, economic, and political welfare of every nation (Bartell, 2003; Bernáld, Cajander, Daniels, \& Laxer, 2011).

Cultural convergence theory also tries to explain cross-cultural understanding. In this theory accord is reached between two or more learners from different cultures through communication and information exchange. Essentially mutual understanding is reached between both parties of different culture. They share, experiences and insights of their own other cultures among themselves and enable the expanding of their cultural awareness and behavior (Gudykunst, Ting-Toomey, \& Chua, 1988; Kincaid, 1979).

According to Yamazaki \& Kayes (2004), and Bloom \& Johnston, 2010 (2004) with cross-cultural learning, learners acquire knowledge through participation, however two main issues arise from this. Textbooks and teachers can be biased towards the host culture and may have only limited cross-cultural knowledge and experience. Thus, cross-cultural programs need to be administering as united, connected events, and as a knowledge-building continuum (Yamazaki \& Kayes, 2004; Bloom \& Johnston, 2010 (2004).

Globalization has brought with it an increase in the internationalization of education, which is reflected in the fast expansion of transnational education, namely educational provision across national and regional borders, and the bourgeoning of international schools worldwide (Starr, 2014). Thus, teachers need to prepare students to communicate thoughtfully, sensitively, and ethically across differences while using a variety of new tools, they also need to engage in these communicative practices themselves (Merryfield, 2003). In the multicultural classroom, where teachers and students originate from different cultures and backgrounds, both students and teachers may approach the situation with different cultural values and expectations about their roles (Mckay, 1993). In 
cross-cultural learning, learners acquire knowledge and skills related to different cultures, and they also absorb new attitudes and values as a result of this experience and participation (Yamazaki \& Kayes, 2004). It is thus vital for educators to teach learners to understand and value the culture of others so that they can interact effectively and comfortably in a world characterized by close multi-faceted relationships and permeable borders (Huang, Chen, \& Mo, 2015).

Cross cultural studies in food science to date have mainly focused on sensory perception, with studies reporting on various basic taste thresholds and taste preferences between different cultural groups, e.g.; Nigerians, Koreans and Americans (Druz \& Baldwin, 1982); Caucasian Australians and Malaysians (Holt et al., 2000); Caucasian Australians and Japanese (Laing et al., 1993, 1994; Prescott \& Bell, 1995; Prescott \& Bell, 1993); Japanese and Americans (Yamaguchi et al. 1988); Malaysian, Chinese and European for aroma-flavour preference of Indian-style and Chinese-style marinated chicken (Yusop et al. 2009ab); Vietnamese and French panellists for soy yogurts (Tu, Valentin, Husson, \& Dacremont, 2010); Korean and French for tea (Kim, Jombart, Valentin, \& Kim, 2013). There have also been examples of reports on food textural preferences, with studies displaying no significant differences between cultures; namely studies done by Jaeger et al. (1998) on the preference patterns of mealiness between British and Danish consumers, and Murray et al. (2000) on textural preference between consumers of European origin and of Chinese origin. Also, differences in cultural preferences have also been reported on taste preferences of aromatic rice (Hori et al., 1994), fruit juice formulation (Abdullah, 1995), snack chips (Ward et al., 1998) and herbal drugs (Pieroni \& Torry, 2007), showing that cultural sensory variation is apparent and context dependant. However, there has been very little, if anything, reported to date on the cross cultural learning experiences of Chinese students studying food science in general. This is important considering the ambitious expansion goals of the School of Food and Nutritional Sciences, University College Cork, with respect to Chinese student numbers. It is hoped that the existing food science programme, through the launch of the new Food Science and Technology Degree (Autumn, 2017) can be expanded to accommodate an additional 25 students per annum from various universities in China.

The objective of this study was to qualitatively determine, using focus groups and semi-structured interviews, the experiences of Chinese third year students studying food science in University College Cork. This was undertaken in order to fully understand the specific learning requirements of these students so that teaching modules can be tailored more to the needs of these specific students both from a structural and teaching perspective. From this an optimised course accommodating both native (Irish) and Chinese students can be designed to facilitate more holistic learning in order to produce high quality food science graduates with the capacity to practice their profession at the highest possible standards. 
The research questions informing the study were as follows:

Overarching research question: How can we optimise the learning of Chinese Students studying food sciences at UCC?

1) Educational background: How does educational background of Chinese students inform their learning in an Irish educational environment?

a) Is it the norm for students to be taught in ways which are greatly different to a Western context?

b) Is critical thinking nurtured and do students have to "obey the teacher?" (Yang, 2008).

c) Is learning based on Confucian heritage cultures where memorization and rote learning involve recitation of Confucian classics? (Cortazzi \& Jin, 1996).

2) What role does a cross-cultural approach play in maximising student learning in Ireland?

3) How can students work with educators at UCC in improving the current offerings to increase student learning for diverse cohorts?

\section{Methodology and Methods}

\subsection{Interviews Using a Structured or Semi-Structured Approach}

Interviewing is one of the most common methods used in small-scale educational research. There are generally two different approaches, "structured", where the Interviewer reads out list of questions and ticks off alternative responses from set of options or "unstructured" where the Interviewer adopts a "non-directive" and conversational style where the interviewee largely determines the course of the discussion. The semi-structured interview is meant to be a personal and intimate encounter in which open, direct, verbal questions are used to elicit detailed narratives and stories and where the interviewer's task is to obtain information while listening and encouraging the interviewee to speak (Di Cicco-Bloom \& Crabtree, 2006). The semi-structured interview gives full freedom to the interviewees to express themselves and to deepen the conversation about some different or all the covered topics. This is important for a good relationship between interviewer and interviewee (Aleandri \& Russo, 2015).

The advantages of structured interviews include that specific information can be collected relatively quickly and is easy to code after the interview and are most useful for gathering short, factual items of information. However, disadvantages of the approach include inflexibility and data collection is also finite, what you ask is what you get.

\subsection{Open-Ended Questions and Closed-Option Questions}

A structured questionnaire was designed using the "Open-Ended" questions highlighted below. Open-Ended Questions are easy to write, allow consumers to respond in their own words and communicate their unbiased opinions and suggestions regarding the product they have been testing (Lawless and Heymann, 1999). Five Chinese students (out of a total potential number of 6), four females 
and one male were recruited from the $3^{\text {rd }}$ year Food Science Degree class, UCC to participate in the interviews. At the end of a mixed class of mainly Irish and these students they were asked if at the next lecture they could voluntarily stay behind so that the present proposal could be presented to them in an unpressured focus group format to encourage their participation. The study was outlined to them during this focus group session with a power-point presentation which clearly defined the principal objective of the study as "the improvement of the degree course to promote more holistic learning for Chinese students". It was emphasised that their participation was purely voluntary and their data would be held in the strictest confidence. During this focus group session, they were informed again that the process was voluntary and that it was ex-curricular to their studies and grades would not be effected in any way through non-participation. The focus group was designed by the first author of the present paper (O'Sullivan, 2017). The students behaved very much like they behave in class, attentive but reluctant to speak up or offer suggestions in the presence of their peers. Thus it was clear that one on one interviews might yield better feedback. A test run, of a designed semi-structured interview, was completed first using a Chinese student volunteer from another course in order to check the effectiveness of the questionnaire. The Interview took from between 35 and 55 minutes and was undertaken in a private quiet office during a time convenient to both the interviewer and interviewee. All interviews were recorded using a sound recorder (Marantz Professional PMD661 MKII Professional Portable Flash Field Recorder) with interviewees informed as such. Pseudonyms (Rachelle, Maisey, Polly, Iris and Corey) were allocated (chosen by interviewee) to each interviewee to keep their anonymity. They all originated their studies in Food Science at BTBU (Beijing Technical and Business University). Three of the students are described as classification $3+1$ ( 3 years study China, 1 year Ireland) and two were $2+1$ ( 2 years study China, 2 years Ireland). The study was submitted and approved by the UCC Social Research Ethics Committee (SREC) with all interviewees granting consent for the use of their interview data (anonymously).

\subsection{Interview Questions}

1) Tell me about your University in China?

2) How do lecturers interact (teach) with students?

3) How do you feel about this? What is your opinion?

4) What do you like and dislike?

5) What would your ideal experience be of learning in English (learning in China and Ireland).

6) How does your classroom experience (so far) in Ireland differ from that of your homeland?

7) How does your laboratory practical experience (so far) in Ireland differ from that of your homeland? 
8) What do you think of UCC approach to teaching? Tell me about your experience of UCC teaching approaches

9) What do you like and dislike. Or what do you find positive and negative about these approaches.

10) How could teaching approaches be improved.

11) What does holistic mean to you? Can you connect the different modules to see the bigger picture.

12) How do you interact with the Irish students. What would you like this interaction to be.

13) Tell me about your exam experience in China and Ireland.

\subsection{Thematic Analysis}

Thematic analysis is a method for identifying, analysing, and reporting patterns (themes) within data (Braun \& Clarke, 2006). It minimally organises and describes data set in (rich) detail and often interprets various aspects of the research topic (Boyatzis, 1998). Thematic analysis can be an essentialist or realist method, which reports experiences, meanings and the reality of participants, or it can be a constructionist method, which examines the ways in which events, realities, meanings, experiences and so on are the effects of a range of discourses where the theme captures something important about the data in relation to the research question, and represents some level of patterned response or meaning within the data set (Braun \& Clarke, 2006). The endpoint is the reporting of the content and meaning of patterns (themes) in the data, where "themes are abstract (and often fuzzy) constructs the investigators identify before, during, and after analysis" (Ryan \& Bernard, 2000).

The interviews for this study were transcribed by the first author in order to create immersion in the data. Hard copies of the interview transcripts were coded by highlighting thematic phrases with a highlighter pen. The interviews were coded and analysed, and the following themes identified as per the results presented below.

\section{Results}

\subsection{General Interaction}

All the Chinese students who participated in the interview sessions were forthright, enthusiastic and very much engaged in the process. They had no difficulty in praising or criticising different aspects of both Irish and Chinese aspects of the interview and for this reason we can have confidence in their honest responses.

\subsection{Theme 1: Educational Background}

\section{Teaching in China}

The participants spoke about their home university context and described BTBU as a mid-ranking University which has two campuses in Beijing-a city campus, described as being quite compact and a country campus in the suburbs to the 
south of the city which is described fondly by all the students as spacious with cleaner air. Classes consist of between 40 and 100 students and start at 8 am and finish at 5:40 pm everyday Monday to Friday, with classes of 40 minutes duration and a very hectic schedule. Occasionally classes are also held in the evenings. A role call is taken at every class with $30 \%$ of final year marks going for attendance. One comment made by the students included;

" $B T B U$ is a good university where we work very hard. We have classes all day, 40 minutes per class and often have classes in the evening and can sometimes finish at 8:00 pm" (Rachelle).

Two interviewees described their teachers as strict with their authority not to be questioned while the rest described their lecturers as overall quite friendly. The former (Rachelle, Maisey, Polly, Iris and Corey) interviewees also said it was hard to ask questions in class as they (and also classmates) did not like to interrupt their lecturer. All described their lecturers as younger than those at UCC with the former only teaching a specific subject. Also lecturers picked random names from the class register to invite students to answer any question they fielded. This had the desired effect of holding the classes' full attention. They were surprised that UCC lecturers can teach more than one topic and were impressed by experience and versatility. Corey's experience of his lecturers in China was overall quite lax, with some of his classmates even sleeping in class. He said his class mates were predominately male. Additional comments made by the students included;

"We are reluctant to ask questions of our teachers in china as we do not wish to annoy them". (Maisey)

"We seldom ask questions as we do not want to question their knowledge". (Polly)

All interviewees described the lecturers in UCC as kind and helpful who appear very competent and experienced. Their lecturers were overall stricter in China which made them more tense, but also it heightened their concentration. Additional comments made by the students included;

"We are alert in class [in China] with especially the strict lecturers because they can ask anyone a question. We are motivated to learn". (Iris)

The interviewees suggested the class timetable in Ireland is more flexible than China, which they like very much. They also like that the lecturers in Ireland have a lot of experience. Maisey described learning by rote in classes in China. She was required to memorise various text books with additional explanation not always offered. Additional comments made by the students also highlighted this experience:

"We are expected to know the textbook in China. It is not necessary to know information outside of this". (Rachelle)

\subsection{Theme 2: Educational Experience}

Learning in Ireland

None of the interviewees have English classes while studying in Ireland. They 
have not been made available. They all proclaimed it would be better if they had English classes, but one interviewee (Corey) insisted it would have to be compulsory and timetabled during the day, as a voluntary evening class would have high absenteeism or attrition. This student also said that his first semester was daunting and because of his English found the course difficult. However, the second semester was better as his English improved. He suggested maybe if more difficult modules could be presented in the second semester and easier ones in the first to facilitate this and a better learning experience for Chinese students. Additional comments made by the students included;

"It took time to understand Irish accent, sometimes people in Cork speak very fast. More so outside of the university". (Polly)

"Some Irish lecturers try to speak more slowly to help us in class". (Maisey)

Both in China and Ireland lecturers use Powerpoint and Blackboard which the interviewees like very much. However, they stressed the importance of being able obtain lecture notes at least a day or two before the lecture especially so that they can translate unfamiliar scientific terms, processes, nomenclature etc. The interviewees described how they sometimes do this in class using Google Translate or electronic dictionaries, but when they do this they can miss out on what the lecturer is saying. WIFI connectivity is thus very important for the latter, however not all classrooms have good WIFI. One particular classroom they highlighted as a black-spot (Food Science Building A1) with no WIFI connectivity.

Also, lecturers who only provide hand-outs during class, they felt, leaves them at a disadvantage, they don't like this at all and reported finding it harder to learn in such circumstances because they have not had time to preview the content and translate for understanding. One student, Polly, said that the background knowledge of the Irish classmates' seemed greater than her own in some topics. She felt it was hard for some students in similar circumstances to progress their understanding in this case. She suggested that courses in Ireland and China should be more aligned so that when the Chinese students come to Ireland they have the same level of background knowledge as their fellow Irish classmates. One interviewee, Polly, said it seemed crazy sometimes the way classes were timetables in UCC. They could have a class in the city and have the next class in the Western Gateway building twenty minutes away and it quite often rains. She found this annoying and frustrating. Additional comments made by the students included;

"I bring my umbrella as it can rain. I don't understand why our lectures can be so far apart. I mean a twenty minute walk between classes is a waste of time and I can get wet". (Polly)

"Sometimes lecturers assume we know important stuff, but we don't. If they could just explain more sometimes." (Polly)

"We should ask more questions in class but do not wish to seem foolish." (Corey). 
"We email a nice lecturer questions who then responds in the next class. He does not say where the question came from, but responds in detail. We learn a lot from him." (Rachelle)

Overall exams in China consist of many MCQ's and short questions which the students are accustomed to. In Irish exams they find the essay type question a very difficult concept to understand especially on first seeing them. Students suggested this has become easier over time, but they prefer the former format of MCQ's and short Questions. They also suggested they would benefit from tutorials where example essay questions are answered by the lecturer as case studies or sample questions format. However, they also mostly said the essay question type format is one where a wide breadth of knowledge is required and that potentially is could improve the quality of their overall understanding, once they have more experience with them. Additional comments made by the students included;

"Essay questions are new for us. They are difficult as we must answer and know everything." (Iris)

"If at the start ( $1^{\text {st }}$ semester) an essay question could be explained how to answer we could be more prepared." (Iris)

"They (essay questions) are difficult, but become easier with time and practice. Tutorials would be good I think and help us if they could be explained." (Corey)

\subsection{Theme 3: Laboratory Practical Experience}

Some of the interviewees described labs as being small but more frequent in China and overall quite easy. Irish labs were more complex and challenging, but the students reported learning more. The interviewees mentioned how in Ireland they received good demonstration and lab instructions and were asked additional questions for their reports to determine their level of understanding which they said was helpful and increased their understanding of the topic in question. However, one student, Rachelle, said they have more autonomy in China, they also worked in pairs, which more facilitated their experiential learning. Masiey found Irish labs difficult to understand, but this student also had the poorest English skills of the group interviewed. Iris also described that in China they could volunteer to assist Postgraduate students in their University with laboratory work in order to gain more experience. Interviewees also described how in China, video is sometimes used to demonstrate labs. Two separate students, Rachelle and Iris, would like to see this done in the lecture preceding the lab to facilitate their understanding. All interviewees said good laboratory manual instructions were the most important component of a successful laboratory practical in order to facilitate understanding. Sometimes in China to pass a lab they just have to copy their manuals. The additional questions asked in Irish labs make them harder but they learn more from them. Additional comments made by the students included; 
"The questions we must answer for lab reports in Ireland are not directly in the manual. We know that out demonstrators are wishing us wider understanding. It can make the report difficult but with wider reading we can answer and learn a lot." (Rachelle)

"We learn much in Irish labs because we must connect information sometimes also from our classes and labs together." (Maisey)

\subsection{Theme 4: University Infrastructures}

Students reported that they sometimes have to translate unfamiliar words in class and do this using Google Translate or electronic dictionaries, while simultaneously trying to listen to the lecture, meaning they can miss out on what the lecturer is saying. WIFI connectivity is thus very important to enable learning for these students however the interviewees reported that not all classrooms have good WIFI. Also teaching in UCC definitely promoted more holistic understanding and unlike some situations in China was never rote learning. Additional comments made by the students included;

"FSB A1 (a 100 seater standard classroom) we hate as no WIFI there. We need this to translate in class sometimes a lot." (Corey)

Students suggested that lecturers who only give out hand-outs during class leaves them at a disadvantage, they don't like this at all and feel they find it harder to learn in such circumstances because they have not had time to preview and translate etc. As described earlier one interviewee, Maisey, also described learning by rote in classes in China as something she disliked. She was required to memorise various text books with additional explanation not always offered. She also expressed her opinion that the lecturers in China cannot be challenged and they are held in very high esteem and thus the student opinion is often ignored. Additional comments made by the students included;

"It is terrible for us when a lecturer does not use Blackboard and then gives out big handouts in class. This is difficult for us." (Maisey)

"It is frustrating sometimes as we cannot prepare in advance." (Maisey)

\subsection{Theme 5: Holistic Learning}

Teaching approaches and "connecting the dots" in the discipline

The students reported how essential it is to get notes in advance of the class so that they can prepare and become familiar with the language and concepts before class. Students also suggested they would like more elective subjects so that they consider specialising in different product areas, perhaps, dairy, meat, beverages, confectionary, ingredients etc. Most of the students had a strong idea where they want to work after graduating and these elective subjects would allow them to specialise to a greater degree. Additional comments made by the students included;

"If we could choose between classes it would be better." (Polly)

"Not everything can be completely relevant to me." (Polly) 
"What we learn in one module can help us in another." (Maisey)

Interviewees understood the concept of holistic learning, when also described as "joining the dots" of the module content to the syllabus. As can be seen above, Maisey clearly understood the concept of applying what she learnt from one module to another. The interviewees presented examples of "cross-pollination" of the way different food science areas are connected, for example, Polly, explained that she understands how microbial spoilage and chemical deterioration of food effect shelf life, and how this manifests as sensory issues and possibly also as food safety issues. She was also able to identify how preservatives help to retard these processes. She was enthusiastic about telling me about these holistic connections in the food science discipline. Additional comments made by the students included;

"Some lecturers say this in class, that we must try and understand holistically. We must connect things, as you say join the dots." (Polly)

"holistic understanding is important to know our topic well." (Polly)

\subsection{Connecting with Locals}

Overall Irish students were described as shy and reserved until approached where then they were quite helpful and friendly. Several interviewees suggested they would like to have more interaction with Irish students. In some lab sessions, local and Chinese students are all mixed to facilitate this, but the interviewees said they would like more interaction both from a cultural and English language learning perspective. Also, some said they had Chinese friends in the $4^{\text {th }}$ year food science class who they would like to learn and/or socially connect with (?). For their final year project their team was always composed of just Chinese students. Three students (Maisey, Polly, Iris) felt they would get more out of being included in a mixed team of both Irish and Chinese students. Also one student (Polly) said Ireland was quiet and peaceful and Irish people friendly. Additional comments made by the students included;

"Irish people are kind. In Beijing students must respect their seniors. We can be shouted at if we ask the wrong person directions." (Rachelle)

"There is never shouting in Ireland." (Rachelle)

"Irish student help us, they are very kind. It is a nice feeling." (Maisey)

"Over time we make more friends (Irish), but it takes time." (Maisey)

\section{Discussion}

Lin (2004) claims that cultural adaptation process includes three separate elements: understand, adjust and learn. Firstly, the host and guest culture need to understand each other in their own terms. Secondly, both cultural groups must possess a capacity for modification or adjustment necessary for smooth interactions. Thirdly, the highest level of adaptation occurs when a party makes a conscious effort to learn from the other party; that is, to integrate elements of the other culture into its own (Lin, 2004). The present study has endeavoured to 
conform to Lin's (2004) suggestions by interviewing from first principals and in an unbiased fashion with the principal aim of learning from both Irish and Chinese cultures. We wish to understand our Chinese students, adjust to their specific requirements, learn from this to optimise our teaching in order to better facilitate their learning. Also, by providing different and diverse methods of disseminating we will be reducing bias within teaching practices and this qualitative study may provide some scientific data which may highlight optimal learning requirements for different nationalities again as suggested by Lin (2004). Students, national and international, will have an individual preference as to how they wish to express themselves. Some may be able to express themselves well in written text but not speech, and vice versa. It should also be recognized that action and expression require a great deal of strategy, practice, and organization, and this is another area in which learners can differ (Cast, 2011). Although not directly asked during the interview process it was clear from the Chinese student's lab reports that they have a high level of mathematical acumen. Multiple Means of Expression provide options for physical action and varied methods for response and navigation in order to optimize access to tools and assistive technologies. Essentially, expression provides options for expression and communication use multiple media for communication and multiple tools for construction and composition (Cast, 2011). Entity learners are more at home in the representational model of understanding, because they expect that they should "get it", that learning is about taking in an entire entity at once, and that the role of teachers is to supply this product, in the form of "the notes" or "set answers". Perhaps European or Irish students may fit this category better than international students, but we should not make assumptions and conduct a scientific study from first principles.

In China teaching methods differ greatly from modern methods practiced in Western society. No critical thinking is nurtured and students have to obey the teacher (Yang, 2008). The Chinese learning strategy is commonly based on Confucian heritage cultures where memorization and rote learning involve recitation of Confucian classics from government approved books without anti-government ideas (Cortazzi \& Jin, 1996). The present study conforms to these views with Chinese students required to know the lab manual verbatim and their reluctance to offer opinions or field questions in class. Again, according to Cortazzi and Jin (1996) rote learning is the mainstay of the Chinese culture of learning, which values collective effort rather than individual responsibility for the learning. Memorizing and rote learning is the Chinese students' main learning method (Ballard \& Clanchy, 1991; Harris, 1997). Thus, academic writing tends to be more reproductive (Waston, 2001). Western practices could not be more different where, teachers encourage students to ask questions, understand concepts rather than knowing facts, and analyze rather than rote learn and are encouraged to develop as independent learners (Yang, 2008). In the present study, Chinese students initially found it difficult to answer question in their 
Irish lab questions, which are designed to facilitate their broader understanding of a topic. These questions were not directly answered in the given lab notes. Students are required to "join the dots" from their cumulative knowledge gained from the lecture (coinciding with the lab session), the lab session itself, or appropriate additional information from other modules. This is the opposite of practice in China, but was something the students found beneficial with practice and something that they could see the value of as a tool for reinforcing this holistic type learning. The underlying assumptions have a great impact on the process of teaching and learning in some multicultural classrooms. Thus in the multicultural classroom, where teachers and students originate from different cultures and backgrounds, both students and teachers may approach the situation with different cultural values and expectations about their roles (Mckay, 1993). From the interview process of the present study it is clear that Chinese students are more reluctant to ask questions or offer their opinion in class. However, they did manage to communicate with one particular lecturer through email, who answered their questions in a professional and non-judgemental fashion. This is something that will be suggested to the lecturing cohort in Food Science in UCC where Chinese students are more actively encouraged to make more private communication to lecturers if they so wish, in order to answer questions or clarify topic.

Griffith and Myers (2005) propose that national cultural norms which are embedded in bilaterally established relational norms and are considered as a part of hybrid organisational cultural norms. Furthermore, Graen, Hui, and Gu (2004) propose a "third culture bonds" model, where the different cultural backgrounds of the host and guest cultural members are synthesized into a new culture that is acceptable to all members. This appears to be the case with the findings of the present study whereby the students are adapting and adopting to their Irish learning experiences but still do this in a very Chinese fashion. For example, they may not like to ask a question in class but will email the lecturer privately so that they he/she can respond to them in the next class.

Additionally various measures to promote reciprocal or mutual learning in transnational education have included advocating pluralistic approaches that celebrate or hybridize the diverse ways of knowing and being (Lai, Li, \& Gong, 2016; Djerasimovic, 2014; Feng, 2013; Zhang, 2015) as well as the promotion of cross-cultural networking groups to promote collegial connectedness (Keay et al., 2014; Keevers et al., 2014) as well as being reflective and undergoing constructive peer scrutiny (Bovill et al., 2015; Howe \& Xu, 2013). However, it is important not to base experimental foundations on stereotypical ideas. Yang (2008) in a critical study of his multicultural classroom of American and Chinese students traditionally, thought Asian students were considered hard working and quiet. However, in his Chinese class, things were often reversed. His Asian students often performed better than others in the beginning, but tended to be passive learners and liked to chat in class and slipped down in their grades. On the 
contrary, he initially thought that American college students did not care about their grades and were too proud and impolite, but in reality found them respectful and obedient to the teachers with some American students often ranking at the top of the class (Yang, 2008). Indeed the literature review for this study, identifies the dangers of accepting stereotypical behaviour as bona fide fact. Incremental learners, on the other hand, come gradually to understand by performing, doing, or engaging in activities that are real within the world that is to be understood (McCarthy, 2008). Perhaps international students better fit this category, but again the learning from this study is based purely on the qualitative data collected as well as anecdotal classroom observations. Teaching methods that promote incremental learning need to be explored and adopted because they allow students to learn at their own pace but should also be structured so that the most critical information is essentially learned and subsequent levels are incrementally added as layers. Mathematical solutions to lab bases calculations certainly appears to suit the Chinese students studied, however they were less enthusiastic regarding essay type answers, as in the exam scenario. This is principally due to a lack of experience. In this scenario the Irish students can be considered the "entity learners" and the Chinese students the "incremental".

China's economic performance over the past few decades has now put it in a position where it now accounts for one-third of global economic growth, twice as much as America which has attracted attention from businesses and investors worldwide from 1979 to 2005, China's GDP grew at an average annual rate of 9.7\% (Morrison, 2006). Additionally, Ireland is well placed to capitalise on international student interest in its third level courses considering the implication of Brexit, in the UK, for the university sector. Soon Ireland may find itself the only EU country with English as the primary language. The UK wishes to retain access to the single market but this requires acceptance of the four EU freedoms, movement of goods, capital, services, and people. The last, movement of people, is the stumbling block with the UK wishing to implement restrictions on immigration. This might also have implications for students who may not feel as welcome in the UK as they have been in the past. For this reason we should be open to investigating the need of international students, similarly to the study presented here, in order to best fit their learning requirements which will be diverse and thus require bespoke teaching solutions. Transnational education programmes can be characterized by unequal power relations among, and disproportionate contributions from, teachers of different cultural backgrounds as well as one-way transmission of the pedagogical practices of the "developed" or host culture (Djerasimovic, 2014; Pyvis, 2011; Kanu, 2011). This can lead to blind and uncritical one-sided learning or stereotypical attitudes towards different practices (Keay et al., 2014; Montgomery, 2014). Strategies need to be developed that openly, honestly, and productively work with differences and manage contrasting ideas and beliefs through discussion and reflection (Grossman, Wineburg, \& Woolworth, 2001). 
Researchers are hence calling for more research into how an important professional development source in the internationalization of education mutual and reciprocal learning among teachers of diverse cultural backgrounds could be maximized (Keevers et al., 2014). This should be undertaken from first principals as sometimes the obvious may be overlooked. I doubt that poor WIFI connectivity was even known to be a potential barrier to learning as determined from the present study. Engaging in dialogue with people who hold different perspectives, and to express differences of opinion in respectful, thoughtful, and ethical ways, is the centrepiece of a cosmopolitan approach to education (Hansen, 2011). However, interactions with different cultural norms of being and knowing are likely to generate dissonances that would stimulate the identification, critical reflection and questioning of (unconscious) assumptions and beliefs about teaching and learning and taken-for-granted practices, which in turn promotes transformational learning (Lai, Li, \& Gong, 2016; Montgomery, 2014; Smith, 2009). Finally, it is important for teachers to experience the guest student's culture by teaching in their country for a period. This can also bolster understanding and facilitate even further understanding of the need of our international students.

- The present study was a "one off"-other studies might look at focus groups or individual interviews conducted over various points in semester to track progress etc.

\section{Conclusion}

The conclusions of this study answer the overarching research question: "How can we optimise the learning of Chinese Students studying food sciences at UCC?" Overall the Chinese students interviewed showed consensus with regard to certain issues with respect to their classes taught in Ireland. It is essential for them that they receive lecture notes with an adequate lead time prior to the lecture. This is important so that they can pre-read and translate sections, words or phrases in to Mandarin Chinese. Also, from the interviews, it was found that good WIFI access is essential to the students during the lecture. Again this facilitates translation using online translational services for unfamiliar words or phrases that lectures might present in class. Exam formats differ between China and Ireland with the latter using more essay type questions which are used to initiate a holistic response from students. However, in China exams are usually presented with short questions. It is recommended that students are introduced to the essay question format, possibly also through tutorials, to speed and ease their transition in the Irish system. Finally, communication with lecturers was facilitated more privately by Chinese students through anonymous email questions subsequently answered in class. Lecturers should be cognisant of this and allow students to communicate in this fashion which fits in to the more private persona Chinese students reflect. However, over time it would be hoped that they become more confident to be able to interact more openly in a classroom 
setting. The above findings will be used to optimise the current interaction with our Chinese students who are studying in the newly launched (September 2017) BSc. in Food Science and Technology International. Thus, the present study will act as a foundation for continued action research, analysis and further optimisation through the voluntary gathering of similar type information from the incoming and future cohorts of Chinese students. In this fashion a bespoke teaching programme for Chinese students can truly be developed.

\section{Conflicts of Interest}

The authors declare no conflicts of interest regarding the publication of this paper.

\section{Funding}

This research did not receive any specific grant from funding agencies in the public, commercial, or not-for-profit sectors.

\section{Limitations of the Study}

- Small group of participants (lack of generalisability).

- The interviewer already had an established rapport with the students - while this is a strength when undertaking interviews this can also influence data collection.

- Students giving answers in a second language could be seen as a limitation it is noted that further studies could be translated into the students' first language and then into English so as to get a richer picture.

\section{References}

Abdullah, A. (1995). Consumer Preferences in Fruit Juice Formulation. Proceedings of the 5th ASEAN Food Conference, 5, 165-170.

Aleandri, G., \& Russo, V. (2015). Autobiographical Questionnaire and Semi-Structured Interview: Comparing Two Instruments for Educational Research in Difficult Contexts. Procedia-Social and Behavioral Sciences, 197, 514-524. https://doi.org/10.1016/j.sbspro.2015.07.179

Ballard, B., \& Clanchy, J. (1991). Teaching Students from Overseas: A Brief Guide for Lecturers and Supervisors. Melbourne: Longman Chesire.

Bartell, M. (2003). Internationalization of Universities: A University Culture-Based Framework. Higher Education, 45, 43-70. https://doi.org/10.1023/A:1021225514599

Bernáld, H., Cajander, A., Daniels, M., \& Laxer, C. (2011). Reasoning about the Value of Cultural Awareness in International Collaboration. Journal of Applied Computing and Information Technology, 15, No. 1.

Bloom, K., \& Johnston, K. M. (2010). Digging into YouTube Videos: Using Media Literacy and Participatory Culture to Promote Cross-Cultural Understanding. Journal of Media Literacy Education, 2, 113-123.

Bovill, C., Jordan, L., \& Watters, N. (2015). Transnational Approaches to Teaching and Learning in Higher Education: Challenges and Possible Guiding Principles. Teaching in Higher Education, 20, 12-23. https://doi.org/10.1080/13562517.2014.945162 
Boyatzis, R. E. (1998). Transforming Qualitative Information: Thematic Analysis and Code Development. Thousand Oaks, CA: Sage.

Braun, V., \& Clarke, V. (2006) Using Thematic Analysis in Psychology. Qualitative Research in Psychology, 3, 77-101. https://doi.org/10.1191/1478088706qp063oa

CAST (2011). Universal Design for Learning Guidelines Version 2.0. Wakefield, MA: CAST.

Cortazzi, M., \& Jin, L. (1996). Cultures of Learning: Language Classrooms in China. In H. Coleman (Ed.), Society and the Language Classroom (pp. 169-206). Cambridge, England: Cambridge University Press.

Di Cicco-Bloom, B., \& Crabtree, B. (2006). The Qualitative Research Interview. Medical Education, 40, 314-321. https://doi.org/10.1111/j.1365-2929.2006.02418.x

Djerasimovic, S. (2014). Examining the Discourse of Cross-Cultural Communication in Transnational Higher Education: From Imposition to Transformation. Journal of Education for Teaching, 40, 204-216. https://doi.org/10.1080/02607476.2014.903022

Druz, L., \& Baldwin, R. (1982). Taste Thresholds and Hedonic Responses of Panels Representing Three Nationalities. Journal of Food Science, 47, 561-569. https://doi.org/10.1111/j.1365-2621.1982.tb10123.x

Feng, Y. (2013). University of Nottingham Ningbo China and Xi'an Jiaotong-Liverpool University: Globalization of Higher Education in China. Higher Education, 65, 471-485. https://doi.org/10.1007/s10734-012-9558-8

Graen, G. B., Hui, C., \& Gu, Q. L. (2004). A New Approach to Intercultural Cooperation. In G. B. Graen (Ed.), New Frontiers of Leadership, LMX Leadership: The Series, Vol. 2 (pp. 225-246). Greenwich, CT: Information Age.

Griffith, D. A., \& Myers, M. B. (2005). The Performance Implications of Strategic Fit of Relational Norm Governance Strategies in Global Supply Chain Relationships. Journal of International Business Studies, 36, 254-269.

https://doi.org/10.1057/palgrave.jibs.8400131

Grossman, P., Wineburg, S., \& Woolworth, S. (2001). Toward a Theory of Teacher Community. Teachers College Record, 103, 942-1012.

https://doi.org/10.1111/0161-4681.00140

Gudykunst, W. B., Ting-Toomey, S., \& Chua, E. (1988). Culture and Interpersonal Communication. Thousand Oaks, CA: Sage Publications Inc.

Hansen, D. T. (2011). The Teacher and the World: A Study of Cosmopolitanism as Education. London: Routledge.

Harris, R. (1997). Overseas Students in the United Kingdom University System. Higher Education, 29, 77-92. https://doi.org/10.1007/BF01384242

Holt, S. H. A., Cobiac, L., Beaumont-Smith, N., Easton, K., \& Best, D. J. (2000). Dietary Habits and the Perception and Liking of Sweetness by Australian and Malaysian Students: A Cross Cultural Study. Food Quality and Preference, 11, 299-312. https://doi.org/10.1016/S0950-3293(99)00076-2

Hori, K., Purboyo, R. B. R., Jo, M., Kim, S., Akinaga, W., Okita, T., \& Kang, M. (1994). Comparison of Sensory Evaluation of Aromatic Rice by Consumers in East and South-East Asia. Journal of Consumer Studies and Home Economics, 18, 135-139. https://doi.org/10.1111/j.1470-6431.1994.tb00682.x

Howe, E. R., \& Xu, S. J. (2013). Trans-Cultural Teacher Development within the Dialectic of the Global and Local: Bridging Gaps between East and West. Teaching and Teacher Education, 36, 33-43. https://doi.org/10.1016/j.tate.2013.06.010 
Huang, Y. M., Chen, M. Y., \& Mo, S. S. (2015). How Do We Inspire People to Contact Aboriginal Culture with Web 2.0 Technology? Computers \& Education, 86, 71-83. https://doi.org/10.1016/j.compedu.2015.03.001

Jaeger, S. R., Andani, Z., Wakeling, I. N., \& Macfie, H. J. H. (1998). Consumer Preferences for Fresh and Aged Apples: A Cross-Cultural Comparison. Food Quality and Preference, 9, 646-649. https://doi.org/10.1016/S0950-3293(98)00031-7

Kanu, Y. (2011). Introduction. In Integrating Aboriginal Perspectives into the School Curriculum: Purposes, Possibilities, and Challenges (pp. 1-29). Toronto: University of Toronto Press.

Keay, J., May, H., \& O’Mahony, J. (2014). Improving Learning and Teaching in Transnational Education: Can Communities of Practice Help? Journal of Education for Teaching, 40, 251-266. https://doi.org/10.1080/02607476.2014.903025

Keevers, L., Lefoe, G., Leask, B., Sultan, F. K. P. D., Danesharatnam, S., Loh, V. et al. (2014). "I Like the People I Work with. Maybe I'll Get to Meet Them in Person One Day": Teaching and Learning Practice Development with Transnational Teaching Teams. Journal of Education for Teaching, 40, 232-250. https://doi.org/10.1080/02607476.2014.903024

Kim, Y. K., Jombart, L., Valentin, D., \& Kim, K. O. (2013). A Cross-Cultural Study Using Napping: Do Korean and French Consumers Perceive Various Green Tea Products Differently? Food Research International, 53, 534-542. https://doi.org/10.1016/j.foodres.2013.05.015

Kincaid, D. L. (1979). The Convergence Model of Communication. East-West Center.

Kittler, P. G., Sucher, K., \& Nelms, M. (2011). Food and Culture. Belmont, CA: Thomson Wadsworth.

Lai, C., Li, Z., \& Gong, Y. (2016). Teacher Agency and Professional Learning in Cross-Cultural Teaching Contexts: Accounts of Chinese Teachers from International Schools in Hong Kong. Teaching and Teacher Education 54, 12-21. https://doi.org/10.1016/j.tate.2015.11.007

Laing, D., Prescott, J., Bell, G., Gillmore, R., Allen, S., \& Best, D. (1994). Responses of Japanese and Australians to Sweetness in the Context of Different Foods. Journal of Sensory Studies, 9, 131-155. https://doi.org/10.1111/j.1745-459X.1994.tb00237.x

Laing, D., Prescott, J., Bell, G., Gillmore, R., James, C., Best, D., Allen, S., Yoshida, M., \& Yamazaki, K. (1993). A Cross Cultural Study of Taste Discrimination with Australians and Japanese. Chemical Senses, 18, 161-168. https://doi.org/10.1093/chemse/18.2.161

Lin, X. H. (2004). Determinations of Cultural Adaptation in Chinese-U.S. Joint Ventures. Cross-Cultural Management, 11, 35-47. https://doi.org/10.1108/13527600410797738

McCarthy, M. (2008). Teaching for Understanding for Lecturers: Towards a Scholarship of Teaching and Learning. In Emerging Issues 11: The Changing Roles and Identities of Teachers and Learners in Higher Education (pp. 101-115). University College Cork: NAIRTL/EDIN.

Mckay, S. L. (1993). Agendas for Second Language Literacy. New York, NY: Cambridge University Press.

Merryfield, M. (2003). Like a Veil: Cross-Cultural Experiential Learning Online. Contemporary Issues in Technology and Teacher Education, 3, 146-171.

Montgomery, C. (2014). Transnational and Transcultural Positionality in Globalised Higher Education. Journal of Education for Teaching, 40, 198-203. https://doi.org/10.1080/02607476.2014.903021

Morrison, W. (2006). China's Economic Conditions. Congressional Research Service: The 
Library of Congress.

Murray, J. M., Easton, K., \& Best, D. J. (2000). A Study of Chinese-Origin and European-Origin Australian Consumers' Texture Preferences Using Novel Extruded Product. Journal of Sensory Studies, 16, 485-504. https://doi.org/10.1111/j.1745-459X.2001.tb00315.x

O'Sullivan, M. G. (2017). CH3. Sensory Affective (Hedonic) Testing. In A Handbook for Sensory and Consumer Driven New Product Development: Innovative Technologies for the Food and Beverage Industry (pp. 39-57). Cambridge: Woodhead Publishing Ltd. https://doi.org/10.1016/B978-0-08-100352-7.00003-8

Pieroni, A., \& Torry, B. (2007). Does the Taste Matter? Taste and Medicinal Perceptions Associated with Five Selected Herbal Drugs among Three Ethnic Groups in West Yorkshire, Northern England. Journal of Ethnobiology and Ethnomedicine, 3, 21. https://doi.org/10.1186/1746-4269-3-21

Prescott, J., \& Bell, G. (1993). Tayloring Food Exports to Japanese Taste Preferences. Search, 24, 161-162, 167-168.

Prescott, J., \& Bell, G. (1995). Cross Cultural Determinants of Food Acceptability: Recent Research on Sensory Perceptions and Preferences. Trends Food Science and Technology, 6, 201-205. https://doi.org/10.1016/S0924-2244(00)89055-X

Pyvis, D. (2011). The Need for Context-Sensitive Measures of Educational Quality in Transnational Higher Education. Teaching in Higher Education, 16, 733-744. https://doi.org/10.1080/13562517.2011.570436

Ryan, G. W., \& H. R. Bernard. (2000). Data Management and Analysis Methods. In N. Denzin, \& Y. Lincoln (Eds.), Handbook of Qualitative Research (2d ed., pp. 769-802). Thousand Oaks, CA: Sage.

Smith, K. (2009). Transnational Teaching Experiences: An Under-Explored Territory for Transformative Professional Development. International Journal for Academic Development, 14, 111-122. https://doi.org/10.1080/13601440902969975

Starr, K. (2014). The Influences and Implications of PISA: An Australian Perspective (p. 19). Board of Editors.

Tu, V. P., Valentin, D., Husson, F., \& Dacremont, C. (2010). Cultural Differences in Food Description and Preference: Contrasting Vietnamese and French Panelists on Soy Yogurts. Food Quality and Preference, 21, 602-610. https://doi.org/10.1016/j.foodqual.2010.03.009

UCC (2018). https://www.ucc.ie/en/medical/interstud/

Ward, C., Resurrection, A., \& Mcwatters, K. (1998). Comparison of Acceptance of Snack Chips Containing Cornmeal, Wheat Flour and Cowpea Meal by US and West African Consumer. Food Quality and Preference, 9, 327-332. https://doi.org/10.1016/S0950-3293(98)00023-8

Waston, J. (2001). Social Constructivism in the Classroom. Support of Learning, 16, 140-147. https://doi.org/10.1111/1467-9604.00206

Yamaguchi, S., Kimura, M., \& Ishii, R. (1988). Comparison of Japanese and American Taste Thresholds. 22nd Japanese Symposium on Taste and Smell, 19, 73-76.

Yamazaki, Y., \& Kayes, D. C. (2004). An Experiential Approach to Cross-Cultural Learning: A Review and Integration of Competencies for Successful Expatriate Adaptation. Academy of Management Learning \& Education, 3, 362-379. https://doi.org/10.5465/amle.2004.15112543

Yang, S. (2008). Narrative of a Cross-Cultural Language Teaching Experience: Conflicts between Theory and Practice. Teaching and Teacher Education, 24, 1564-1572. 
https://doi.org/10.1016/j.tate.2007.12.003

Yusop, S. M., O’Sullivan, M. G., Kerry, J. F., \& Kerry, J. P. (2009a). Sensory Evaluation of Indian-Style Marinated Chicken by Malaysian and European Naïve Assessors. Journal of Sensory Studies, 24, 269-289. https://doi.org/10.1111/j.1745-459X.2009.00210.x

Yusop, S. M., O’Sullivan, M. G., Kerry, J. F., \& Kerry, J. P. (2009b). Sensory Evaluation of Chinese-Style Marinated Chicken by Chinese and European Naïve Assessors. Journal of Sensory Studies, 24, 512-533. https://doi.org/10.1111/j.1745-459X.2009.00224.x

Zhang, Z. (2015). Chinese and Canadian Teacher Implement a Hybrid Sino-Canadian Curriculum: A Multiliteracies Perspective. Teaching and Teacher Education, 48, 106-116. https://doi.org/10.1016/j.tate.2015.02.006 